\title{
Characterization of Nanosized Nickel Prepared by Surface Reactions of Ni-o-organyl Complexes on Silica: An Electron Paramagnetic and Ferromagnetic Resonance Study
}

\author{
Helmuth Drevs, ${ }^{1}$ Wolfgang Mörke, ${ }^{2 *}$ Jens Jarsetz, ${ }^{2}$ Tomasz Bieruta ${ }^{2}$ and \\ Herbert Hofmeister ${ }^{3}$ \\ ${ }^{1}$ Fachhochschule Merseburg, Martin-Luther-Universität, Geusaer Str., D-06217 Merseburg, Germany \\ ${ }^{2}$ Fachbereich Chemie, Martin-Luther-Universität, Geusaer Str., D-06217 Merseburg, Germany \\ ${ }^{3}$ Max-Planck-Institut für Mikrostrukturphysik, Weinberg 2, D-06120 Halle (Saale), Germany
}

Dispersed atomic nickel $(0)$ is formed during the reaction of the nickel- $\sigma$-organyl complexes with silanol groups at temperatures below $373 \mathrm{~K}$. That nickel is oxidized to $\mathrm{Ni}(\mathrm{I})$ by protons of the silanol groups in a consecutive step. The $\mathrm{Ni}(\mathrm{I})$ portion amounts to about $70 \% \mathrm{w} / \mathrm{w}$ of the $\mathrm{Ni}$ used. Six different $\mathrm{Ni}(\mathrm{I})$ species are detected by electron paramagnetic resonance. They are stabilized by interaction with the silica surface and the organic moieties; they act as anchor ions for the $\mathrm{Ni}(0)$ atoms. $\mathrm{Ni}(0)$ crystallites stabilized in this way are about $0.5 \mathrm{~nm}$ in diameter after a treatment at $373 \mathrm{~K}$. The influence of the $\mathrm{Ni}(\mathrm{I})$ ions on the collective, magnetic properties of the clusters is revealed by calculation of ferromagnetic resonance (FMR) spectra using the independent-grain approach according to Schlömann and Kotyukov. A strain of about $10 \mathrm{GPa}$ is brought about in the nickel crystallites by the interaction with $\mathrm{Ni}(\mathrm{I})$ ions. (C) 1998 John Wiley \& Sons, Ltd.

Appl. Organometal. Chem. 12, 321-325 (1998)

Keywords: Nickel- $\sigma$-organyl complexes; dispersed atomic $\mathrm{Ni}(0)$; $\mathrm{Ni}(\mathrm{I})$ ions; silica; EPR; FMR; spectrum calculation; strain

Received 28 November 1997; accepted 22 January 1998

\footnotetext{
* Correspondence to: W. Mörke, Fachbereich Chemie, MartinLuther-Universität, Geusaer Str., D-06217 Merseburg, Germany. Contract/grant sponsor: Kultus Ministerium of Sachsen-Anhalt; Contract/grant number: 1564A/0024.
}

\section{INTRODUCTION}

To prepare metal particles in a well controlled way, attempts have been made to deposit them on highsurface-area supports (1) by decomposition of metal carbonyls, (2) by surface reactions of organometallic complexes, 2,3 (3) by adsorption of dispersed metal clusters, ${ }^{4,5}$ (4) by metal vapour condensation techniques ${ }^{6}$ and (5) by a two-step variant of the normal sequence of chemical operations to produce a metal/support catalyst, i.e. impregnation (precipitation, ion exchange), oxidation and reduction ${ }^{7}$.

In this paper we report on the preparation of highly dispersed $\mathrm{Ni}$ clusters on silica formed by surface reactions of nickel- $\sigma$-organyl complexes, and the reaction of $\mathrm{Ni}(0)$ with silanol groups forming $\mathrm{Ni}(\mathrm{I})$ ions, which act as anchor atoms for the Ni crystallites.

\section{EXPERIMENTAL}

We used silica gel from Merck (Kieselgel 60, grain size $0.06-0.2 \mu \mathrm{m}$ ) as the support. Silica gel was treated for $4 \mathrm{~h}$ in vacuum at $673 \mathrm{~K}$, cooled to room temperature and loaded in an argon atmosphere with a solution of nickel- $\sigma$-organyl complex in tetrahydrofuran (THF). For drying and for removal of the organic moieties the sample was heated in vacuum, Ar or $\mathrm{H}_{2}$ at $373 \mathrm{~K}$ (labelled as $\mathrm{Ni} 100 \mathrm{~V}$, Ni $100 \mathrm{Ar}$ or $\mathrm{Ni} 100 \mathrm{H}$, respectively) and sealed in glass tubes before electron paramagnetic (EPR) or ferromagnetic (FMR) resonance and electron microscopy measurements. The nickel loading is 


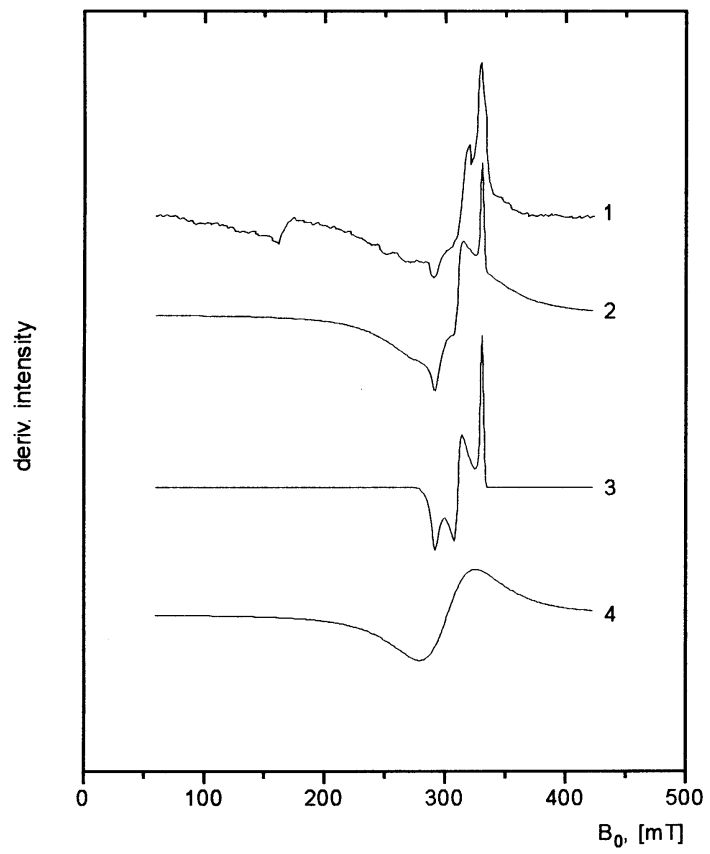

Figure 1 Experimental (1) and calculated (2) EPR powder spectrum of Ni $100 \mathrm{~V}$. Curve 2 was calculated by superposition of $3\left[\mathrm{Ni}^{+}(\equiv \mathrm{SiO})\left(\mathrm{O}_{2}\right) ; g_{1}{ }^{\mathrm{G}}=2.28, \Delta B_{1}=4 \mathrm{mT} ; g_{2}{ }^{\mathrm{G}}=2.14\right.$, $\left.\Delta \mathrm{B}_{2}=3 \mathrm{mT} ; g_{3}{ }^{\mathrm{G}}=2.01, \Delta B_{3}=0.5 \mathrm{mT}\right]$ and $4[\mathrm{Ni}(0)$ signal; for parameters see Table 3].

about $2 \% \mathrm{w} / \mathrm{w}$. EPR investigations were performed at $123 \mathrm{~K}$, using an X-band spectrometer (ERS 220, ZWG Berlin-Adlershof).

Transmission electron microscopy (TEM) was carried out with a JOEL $100 \mathrm{C}$ microscope. The synthesis of the nickel- $\sigma$-organyl complex $\left(\mathrm{Li}_{2}\left[\mathrm{Ni}(\mathrm{DPE})_{2}\right] \cdot 4 \mathrm{THF} ; \mathrm{DPE}=2,2^{\prime}\right.$-dianion of the diphenyl ether) is reported in detail in Ref. 8.

\section{RESULTS AND DISCUSSION}

The hydrolysable nickel- $\sigma$-organyl complexes react with silanol groups forming $\mathrm{Ni}(0)$ (Eqn $[1]^{2,3,8}$

$$
\begin{gathered}
\mathrm{Li}_{2}\left[\mathrm{NiR}_{4}\right]+2 \equiv \mathrm{SiOH} \rightarrow 2 \equiv \mathrm{SiOLi}+ \\
2 \mathrm{HR}+\mathrm{R}-\mathrm{R}+\mathrm{Ni}(0)
\end{gathered}
$$

In the case of $\mathrm{Li}_{2}\left[\mathrm{Ni}(\mathrm{DPE})_{2}\right] \cdot 4 \mathrm{THF}(\mathbf{1})$, the results of the gas-chromatographic analysis ${ }^{8}$ [diphenyl ether $\left(\mathrm{H}_{2} \mathrm{DPE}\right)$ dibenzofuran $(\mathrm{DBF})$ were estimated in both the expected quantities and in the

(C) 1998 John Wiley \& Sons, Ltd.

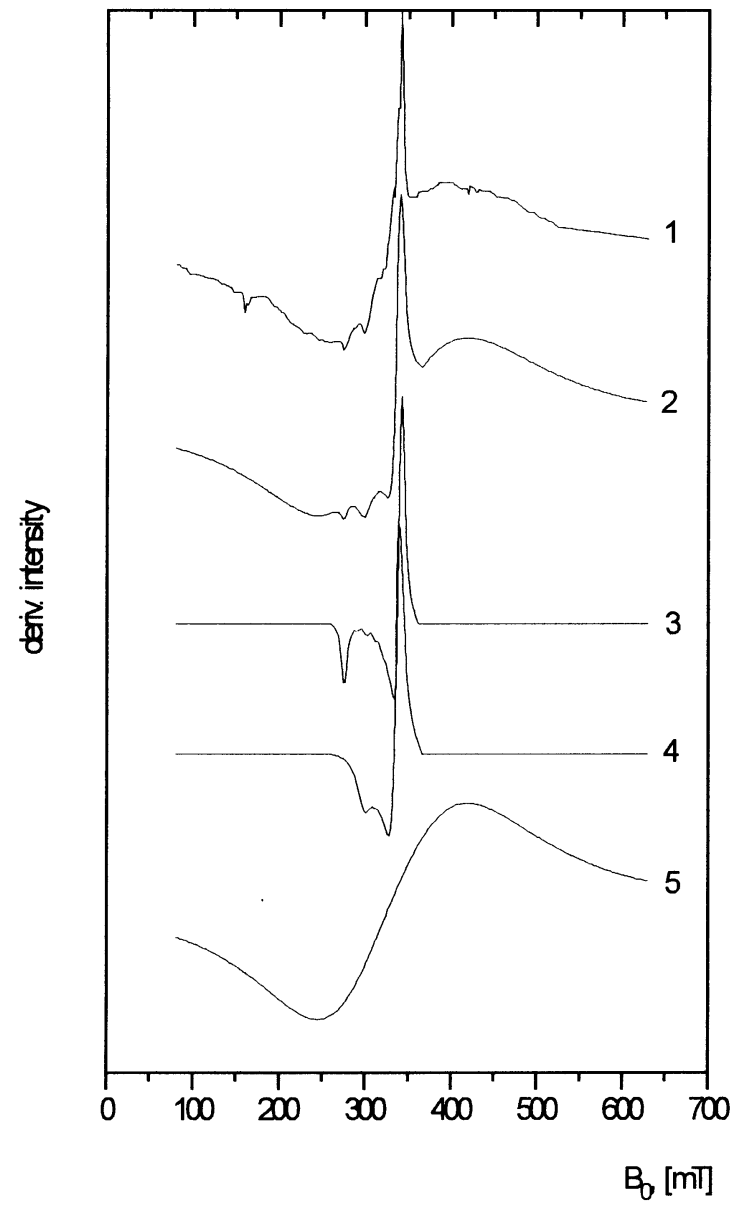

Figure 2 Experimental (1) and calculated (2) EPR powder spectrum of $\mathrm{Ni} 100 \mathrm{Ar}$. Curve (2) was calculated by superposition of $3\left[\mathrm{Ni}^{+}(\equiv \mathrm{SiO}-)(\mathrm{DPE}) \mathrm{Li}_{2} ; g_{\|}{ }^{\mathrm{C}}=2.41, \Delta B_{\|}=4 \mathrm{mT}\right.$; $\left.g_{\perp}{ }^{\mathrm{C}}=1.95, \Delta B_{\perp}=5 \mathrm{mT}\right], 4\left[\mathrm{Ni}^{+}(\equiv \mathrm{SiO}-)_{2} \quad(\mathrm{DPE}) \mathrm{Li}_{2}\right.$; $\left.g_{\|}^{\mathrm{E}}=2.22, \Delta B_{\|}=11 \mathrm{mT} ; g_{\perp}{ }^{\mathrm{E}}=1.97, \Delta B_{\perp}=7 \mathrm{mT}\right]$ and 5 [an $\mathrm{Ni}(0)$ signal; for parameters see Table 3 ].

ratio 1:1] point to the reactions represented by Eqns [2] and [3].

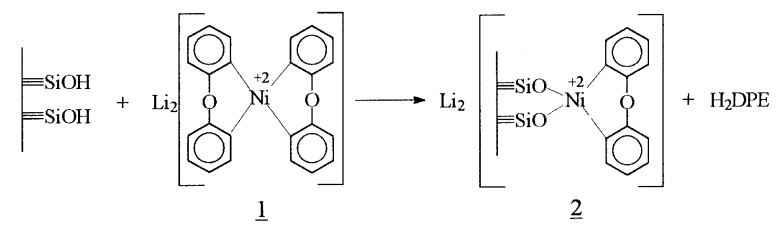

First of all, the surface complex $\mathbf{2}$ is formed. This complex decays by homolysis of the remaining two

Appl. Organometal. Chem. 12, 321-325 (1998) 


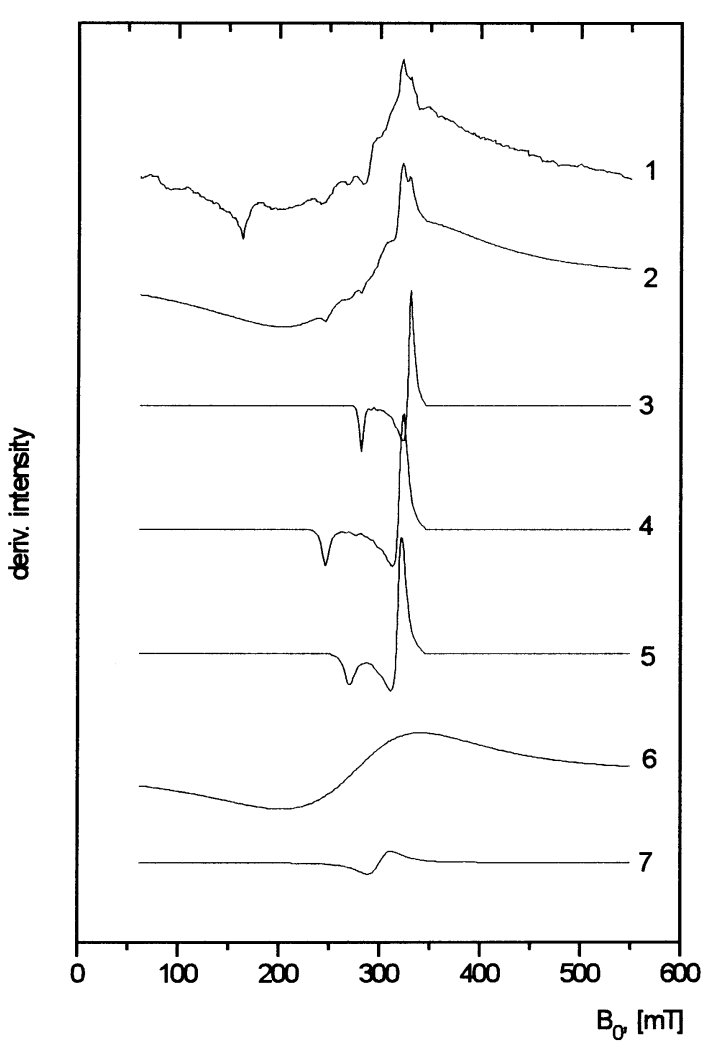

Figure 3 Experimental (1) and calculated (2) EPR powder spectrum of $\mathrm{Ni} 100 \mathrm{H}$. Curve 2 was calculated from $3\left[\mathrm{Ni}^{+}\right.$ $(\equiv \mathrm{SiO}-)(\mathrm{THF})_{x} ; \quad g_{\|}{ }^{\mathrm{B}}=2.36, \quad \Delta B_{\|}=2 \mathrm{mT} ; \quad g_{\perp}{ }^{\mathrm{B}}=2.02$, $\left.\Delta B_{\perp}=4 \mathrm{mT}\right], 4\left[\mathrm{Ni}^{+}(\equiv \mathrm{SiO}-)_{x} ; g_{\|}^{\mathrm{A}}=2.71, \Delta B_{\|}=4 \mathrm{mT}\right.$; $\left.g_{\perp}{ }^{\mathrm{A}}=2.07, \quad \Delta B_{\perp}=6 \mathrm{mT}\right], \quad 5 \quad\left[N i^{+} \quad(\equiv \mathrm{SiO}-)_{\mathrm{y}} \quad(\mathrm{THF})_{x} ;\right.$ $\left.g_{\|}{ }^{\mathrm{D}}=2.46, \Delta B_{\|}=6 \mathrm{mT} ; g_{\perp}{ }^{\mathrm{D}}=2.08, \Delta B_{\perp}=6 \mathrm{mT}\right], 6[\mathrm{Ni}(0) ;$ for parameters see Table 3] and 7 [a paramagnetic Ni(0) signal; $\left.g=2.22, \Delta B_{\mathrm{pp}}=20 \mathrm{mT}\right]$.

$\mathrm{Ni}-\mathrm{C}$ bonds, forming $\mathrm{DBF}$ and dispersed atomic nickel.

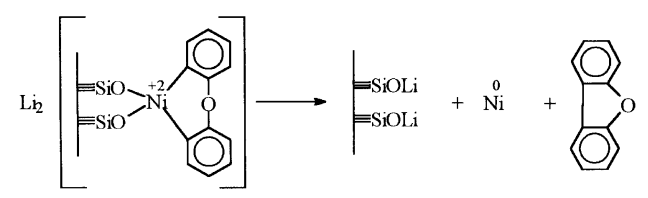

Electron Paramagnetic resonance (EPR) measurements of the Ni 100 samples yield the spectra 1 in Figs 1-3. Inspection of these spectra revealed that they consist of both paramagnetic $\mathrm{Ni}(\mathrm{I})$ and superparamagnetic $\mathrm{Ni}(0)$ signals. This result points to the greater complexity of the surface reactions, and we have to take into consideration the $\mathrm{Ni}(\mathrm{I})$ formation reactions too.
There are several paths to generation of $\mathrm{Ni}(\mathrm{I})$ species in the system under investigation:

(1) the nickel complex $\left(\mathrm{Li}_{2}\left[\mathrm{Ni}(\mathrm{DPE})_{2}\right] \cdot 4 \mathrm{THF}\right)$ can react with one or three silanol groups forming $\mathrm{Ni}(\mathrm{I})$ according to Eqns [4] and [5]:

$$
\begin{gathered}
\mathrm{Li}_{2}\left[\mathrm{Ni}(\mathrm{DPE})_{2}\right]+\equiv \mathrm{SiOH} \rightarrow \equiv \mathrm{SiOLi}+ \\
\mathrm{Li}[\mathrm{Ni}(\mathrm{DPE})]+\mathrm{HDPE} . \\
\mathbf{4} \\
\mathrm{Li}_{2}\left[\mathrm{Ni}(\mathrm{DPE})_{2}\right]+3 \equiv \mathrm{SiOH} \rightarrow 2 \equiv \mathrm{SiOLi}+ \\
\mathrm{H}_{2} \mathrm{DPE}+\underset{\mathrm{SiONi}+\mathrm{HDPE}}{\mathbf{5}}
\end{gathered}
$$

Accordingly radicals and $\mathrm{Ni}(\mathrm{I})$ species $(\mathbf{4}$ and 5) should be generated to the same extent. However, from inspection of both the experimental spectra and the calculated spectra $^{9}$ (see Figs 1-3) it follows that in the Ni 100 samples the quantity of organic radicals can be neglected.

(2) Another possible explanation for the high $\mathrm{Ni}(\mathrm{I})$ content is the re-oxidation of the dispersed atomic $\mathrm{Ni}(0)$ by protons of the silanol groups (Eqn [6]).

$$
\mathrm{Ni}(0)+\equiv \mathrm{SiOH} \rightarrow \equiv \mathrm{SiONi}+\mathrm{H} \cdot
$$

Reaction [6] was observed on NiPd-containing zeolites at $773 \mathrm{~K} .{ }^{10}$ It is well known, however, that in the case of silver atoms in aqueous solutions ${ }^{11}$ the analogous reaction takes place at room temperature. So we suppose that the majority of the $\mathrm{Ni}(\mathrm{I})$ is formed by reaction [6]. The hydrogen radicals are not stable; they recombine with each other or with the HDPE radicals.

The Ni(I) species 5 (species A in Table 1) have some vacancies in their coordination sphere. These vacancies are filled by interactions (1) with organic moieties ${ }^{12-17}$ e.g. solvent molecules (species B in Table 1) or ligand molecules (species C in Table 1), (2) with both further silanol groups, analogously to $\mathrm{Cu}(\mathrm{II}),{ }^{18,19}$ and further organic moieties (species D and $\mathrm{E}$ in Table 1), (3) with each other, pair formation resulting in a signal at half-field ${ }^{20}$ (species F in Table 1), (4) with molecules captured from the atmosphere ${ }^{12,21}$ (species G in Table 1) and (5) with $\mathrm{Ni}(0)$ atoms, giving a signal attributable to paramagnetic or superparamagnetic Ni clusters (see spectra 4,5 and 6,7 in Fig. 1, 2 and 3 respectively).

All interactions (1)-(5) occur in parallel under our experimental conditions. From this it follows 
Table 1 Components of the $g$ tensors for supported $\mathrm{Ni}^{+}$species

\begin{tabular}{|c|c|c|c|c|c|}
\hline Species $^{\mathrm{a}}$ & Code & $g_{3} / g_{\|}$ & $g_{2}$ & $g_{1} / g^{\perp}$ & References \\
\hline $\mathrm{Ni}^{+}(\equiv \mathrm{SiO}-)_{x}$ & A & 2.71 & & 2.07 & $12-14$ \\
\hline $\mathrm{Ni}^{+}(\equiv \mathrm{SiO}-)(\mathrm{THF})_{x}$ & $\mathrm{~B}$ & 2.46 & & 2.08 & This work \\
\hline $\mathrm{Ni}^{+}(\equiv \mathrm{SiO}-)(\mathrm{DPE}) \mathrm{Li}_{2}$ & $\mathrm{C}$ & 2.41 & & 1.95 & This work \\
\hline $\mathrm{Ni}^{+}(\equiv \mathrm{SiO}-)_{y}(\mathrm{THF})_{x}$ & $\mathrm{D}$ & 2.36 & & 2.02 & This work \\
\hline $\mathrm{Ni}^{+}(\equiv \mathrm{SiO}-)_{2}(\mathrm{DPE}) \mathrm{Li}_{2}$ & $\mathrm{E}$ & 2.22 & & 1.97 & This work \\
\hline$\left(\equiv \mathrm{SiO}-\mathrm{Ni}^{+}\right)_{2}$ & $\mathrm{~F}$ & - & & 4.3 & 20 \\
\hline $\mathrm{Ni}^{+}(\equiv \mathrm{SiO})\left(\mathrm{O}_{2}\right)$ & $\mathrm{G}$ & 2.28 & 2.14 & 2.01 & 12,21 \\
\hline
\end{tabular}

${ }^{\mathrm{a}}(x \geq 1 ; \mathrm{y} \geq 2$.

Table 2 Nickel particle size estimated by transmission electron microscopy

\begin{tabular}{lc}
\hline Sample & Size $(\mathrm{nm})$ \\
\hline Ni $100 \mathrm{H}$ & $<1$ \\
Ni 100 V & $<1$ \\
Ni 100 Ar & $<1$ \\
Ni 300 V & $<1$ \\
Ni 300 Ar & $2-4$ \\
\hline
\end{tabular}

that the best fit of the experimental spectra in the region $2.74 \geq g \geq 1.95$ is obtained by superposition of several $\mathrm{Ni}(\mathrm{I})$ signals. Only in the case of the sample $\mathrm{Ni} 100 \mathrm{~V}$ is one $\mathrm{Ni}(\mathrm{I})$ species sufficient to achieve a good fit.

The presence of a larger amount of $\mathrm{Ni}(\mathrm{I})$ is manifested by the small particle size of the $\mathrm{Ni}(0)$ species (see below), the high thermal stability of their dispersity (see Table 2) and the effect of $\mathrm{Ni}(\mathrm{I})$ on them, resulting from the spectrum calculation. $^{22-25}$ The collective magnetic components appear if the calculated $\mathrm{Ni}(\mathrm{I})$ signals are subtracted from the experimental spectra [see the signals of $\mathrm{Ni}(0)$ in Figs 1-3]. The signals of the collective magnetic $\mathrm{Ni}(0)$ components are nearly isotropic at a measurement temperature of $123 \mathrm{~K}$. This low anisotropy agrees with the parameter sets used to calculate the spectra (Table 3).

Thus the value of the magnetocrystalline anisotropy $\left(K_{0}=0.0001\right.$ at $123 \mathrm{~K}$, Table 3$)$ deduced from the spectra calculation corresponds to a particle size smaller than $0.5 \mathrm{~nm},{ }^{26}$ in agreement with the results of the TEM investigations. $K_{\sigma 1}$ and $K_{\sigma 1}$ are the isotropic and the anisotropic parts, respectively, of the magnetoelastic interaction, $\sigma$ is an isotropic ${ }^{24}$ strain or stress $(\sigma>0$ or $\sigma<0)$. To estimate a rough measure of the resulting strain we used the isotropic part $\left(K_{\sigma 1}\right)$ of the magnetoelastic interaction (see Table 3). The actual value of $\sigma$ calculated from $K_{\sigma 1}$ is determined by the sum of three main factors of influence: (1) the differences in the thermal expansion of nickel and $\mathrm{SiO}_{2}$ cause a strain, ${ }^{25,27}$ (2) the surface tension of small particles is dependent on particle size and results in stress, ${ }^{28}$ and (3) the presence of unreduced cations $\left(\mathrm{Ni}^{+}\right)$in nickel crystallites causes a tension. ${ }^{29}$ Both of the factors (1) and (2) are about $5 \times 10^{8}$ and $-10^{10} \mathrm{~Pa}$, respectively, and constant in our samples. The influence of the anchor atoms $\left(\mathrm{Ni}^{+}\right.$ions) and the atmosphere results from the subtraction of these two values from $\sigma$ estimated from $K_{\sigma 1}$. Thus the following sequence of $\sigma$ was obtained: Ni $100 \mathrm{Ar}$, about $9.54 \times 10^{9} \mathrm{~Pa}$; Ni $100 \mathrm{~V}$, about $9.49 \times$ $10^{9} \mathrm{~Pa}$; and $\mathrm{Ni} 100 \mathrm{H}$, about $9.3 \times 10^{9} \mathrm{~Pa}$. The positive sign shows the dominant influence of unreduced $\mathrm{Ni}(\mathrm{I})$ in our samples. The positively charged $\mathrm{Ni}(\mathrm{I})$ ions withdraw electron density from the nickel atoms in the particle. This results in incompletely screened nickel atoms, which try to increase their equilibrium distance and cause a tensile stress within the particles. ${ }^{29}$ The $\sigma$ values given above reveal that differences in the pretreatment (Ar, $\mathrm{H}_{2}$ and $\mathrm{V}$, respectively) influence the resulting strain to a minor degree. Taking into

Table 3 Parameters of spectral simulations of the collective magnetic nickel clusters in Figs 1-3

\begin{tabular}{lcccrrrr}
\hline Sample & $g_{0}$ & $W(\mathrm{mT})^{\mathrm{a}}$ & $K_{0}$ & \multicolumn{1}{c}{$K_{\sigma 1}$} & \multicolumn{1}{c}{$K_{\sigma 1}$} & $K_{3}$ & $\mathrm{gf}^{\mathrm{b}}$ \\
\hline Ni 100 V & 2.22 & 22.83 & 0.0001 & 0.0089 & 0.0012 & -0.0100 & 0.0018 \\
Ni 100 Ar & 2.22 & 68.75 & 0.0001 & -0.0296 & -0.0042 & -0.1196 & 0.0390 \\
Ni 100 H & 2.22 & 60.72 & 0.0001 & 0.1479 & 0.0207 & -0.0813 & 0.0219 \\
\hline
\end{tabular}

${ }^{\mathrm{a}} W=$ half-width of the Lorentz line form function
${ }^{\mathrm{b}} \mathrm{g}=$ goodness of the fit is given by the approximation error $\left[\left(I_{\mathrm{rel}}{ }^{\text {exp }}-I_{\mathrm{rel}}{ }^{\mathrm{cal}}\right)^{2} /(n-1)\right]^{1 / 2}$, where $n$ is the number of data points.

(C) 1998 John Wiley \& Sons, Ltd. 
consideration an uncertainty of about $30 \mathrm{MPa}$ in the estimation of $\sigma,^{30}$ the influence of traces of oxygen (see Ni 100 V, Fig. 1) and that of an Ar atmosphere cannot be distinguished from the stress state of the $\mathrm{Ni}(0)$ particles in the presence of much $\mathrm{Ni}(\mathrm{I})$.

As expected from Eq. [6], the tensile constraints of $\mathrm{Ni}(\mathrm{I})$ are reduced in the case of $\mathrm{Ni} 100 \mathrm{H}$. The decrease in the tension, however, is small $\left(9.5 \times 10^{9}-9.3 \times 10^{9}=2 \times 10^{8} \mathrm{~Pa}\right)$ because of a multitude of $\mathrm{Ni}(\mathrm{I})$ already existing in this sample (see Fig. 3).

However, the hydrogen atmosphere has an influence on the magnetization of the nickel particles too. This circumstance brings about an additional signal of paramagnetic $\mathrm{Ni}(0)$ (see Fig. 3 spectrum 7) compared with the samples Ni $100 \mathrm{~V}$ and $\mathrm{Ni} 100 \mathrm{Ar}$. The presence of paramagnetic $\mathrm{Ni}(0)$ is explained by the filling of the d-band hole of nickel with electron density from the hydrogen selectron $^{31}$ during the adsorption. So the magnetic properties of the nickel particles change from ferromagnetic to paramagnetic with increasing amounts of adsorbed hydrogen. Taking into account the existence of a particle size distribution of the nickel crystallites, the smallest ones should behave paramagnetically. For this reason the paramagnetic nickel signal is observed in this sample.

$K_{3}$ describes the shape anisotropy of an ellipsoidal single-domain particle. $K_{3}<0$ corresponds to an oblate specimen. ${ }^{32}$ The values of $K_{3}$ (see Table 3 ) are typical for nearly spherical particles.

Acknowledgments This study was supported by the Kultus Ministerium of Sachsen-Anhalt under grant 1564A/0024. The authors are grateful to Professor Köhler (München) for supplying the EPR program and to Mrs Mertsching (Merseburg) for her help with the EPR measurements.

\section{REFERENCES}

1. Z. Zhang, S. L. Suib, Y. D. Zhang, W. A. Hines and J. I. Budnik, J. Am. Chem. Soc. 110, 5569 (1988).

2. W. Mörke and H. Drevs, Z. Chem. 25, 453 (1985).

3. W. Mörke and H. Drevs, Z. Chem. 26, 343 (1986).

4. H. Bönnemann, W. Brijoux, R. Brinkmann, E. Dinjus, R.
Fretzen, T. Joußen and B. Korall, J. Mol. Catal. 74, 323 (1992).

5. G. Schmid, H. Harms, J.-O. Malm, J. Bovin, J. v. Ruitenbeck, H. W. Zandbergen and W. T. Fu, J. Am. Chem. Soc. 115, 2046 (1993).

6. H. Poppa, Catal. Rev.-Sci. Eng. 35, 359 (1993).

7. M. Che, Z. X. Cheng and C. Louis, J. Am. Chem. Soc. 117, 2008 (1995).

8. H. Drevs, Thesis, Technische Hochschule "Carl Schorlemmer", Merseburg, 1987.

9. L. K. White and R. L. Belford, J. Am. Chem. Soc. 98, 4428 (1976).

10. J. S. Feely and W. M. H. Sachtler, Zeolites 10, 739 (1990).

11. A. Henglein, Curr. Chem. 143, 113 (1988).

12. W. Bogus and L. Kevan, J. Phys. Chem. 93, 3223 (1989).

13. M. Hartmann, A. Pöppl and L. Kevan, J. Phys. Chem. 99, 17494 (1995).

14. H. Yamada, N. Azuma and L. Kevan, J. Phys. Chem. 98, 13017 (1994).

15. L. Bonneviot and D. Olivier, J. Chem. Soc., Chem. Commun. 952 (1982).

16. A. Barth, R. Kirmse and J. Stach, Z. Chem. 24, 195 (1984).

17. L. Bonneviot, D. Oliver and M. Che, J. Mol. Catal. 21, 415 (1983).

18. W. Mörke, F. Vogt, K.-P. Wendland and I. Achkar, Z. Chem. 30, 297 (1990).

19. H. Motschi, Colloids and Surfaces 9, 333 (1984).

20. K. Nag and A. Chakravorty, Coord. Chem. Rev. 33, 87 (1980).

21. V. B. Kazansky, I. V. Elev and B. N. Shelimov, J. Mol. Catal. 21, 265 (1983).

22. G. Suran, A. Stankoff and F. Hoffmann, Phys. Rev B 8, 1109 (1973).

23. V. K. Sharma and A. J. Baiker, J. Chem. Phys. 75, 5596 (1981).

24. Yu. Kotyukov and V. Abrasov, Sov. J. Phys. 15, 1 (1972).

25. W. Mörke, T. Bieruta, J. Jarsetz, C. Görsmann and U. Schubert, Colloids and Surfaces A 115, 303 (1996).

26. R. S. De Biasi and T. C. Devezas, J. Appl. Phys. 49, 2466 (1978).

27. K. L. Chopra, Thin Film Phenomena, McGraw-Hill, New York, 1979, p. 271.

28. J. S. Vermaak, C. W. Mays and D. Kuhlmann-Wilsdorf, Surf. Sci. 12, 128 (1968).

29. W. Mörke, R. Lamber, U. Schubert and B. Breitscheidl, Chem. Mat. 6, 1659 (1994).

30. M. M. J. Janssen, J. Appl. Phys. 41, 384 (1970).

31. G. C. Bond, Catalysis by Metals, Academic Press, New York, 1962, p. 471.

32. A. H. Morrish, The Physical Principles of Magnetism, Wiley, New York, 1965, p. 332 ff. 